\title{
A Longitudinal Investigation of Sleep and Technology Use in Early Adolescence: Does
} Parental Control of Technology Use Protect Adolescent Sleep?

Richardson, $\mathrm{C}^{1,2}$., Magson, $\mathrm{N}^{2}$., Fardouly, $\mathrm{J}^{2}$., Oar, $\mathrm{E}^{2}$., Johnco, $\mathrm{C}^{2}$. \& Rapee, $\mathrm{R}^{2}$.

${ }^{1}$ Centre for Sleep Science, School of Psychological Science, University of Western Australia, Perth, WA, Australia.

${ }^{2}$ Centre for Emotional Health, Department of Psychology, Macquarie University, Sydney, NSW, Australia

Corresponding Author:

Dr Cele Richardson, M304, 35 Stirling Highway, University of Western Australia, Perth, WA, 6009. Email: cele.richardson@uwa.edu.au. 


\begin{abstract}
Objective: A bi-directional relationship between technology use and adolescent sleep is likely, yet findings are mixed, and it is not known whether parental control of technology use can protect sleep. The current study examined bi-directionality between technology use on school nights and morning/eveningness, sleep duration and daytime sleepiness in early adolescents. We also examined whether time spent using technology mediated the relationship between parental control of technology and adolescent sleep. Methods: Adolescents and their primary caregiver (96\% mothers) completed questionnaire measures of sleep, technology use and parental control across three, annual waves: Wave $1\left(\mathrm{~N}=528, \mathrm{M}_{\mathrm{age}}\right.$ $=11.18, \mathrm{SD}=0.56$, range $=10-12,51 \%$ male $),$ Wave $2\left(\mathrm{~N}=502, \mathrm{M}_{\text {age }}=12.19, \mathrm{SD}=0.53\right.$, $52 \%$ male $)$ and Wave $3\left(\mathrm{~N}=478, \mathrm{M}_{\mathrm{age}}=13.19, \mathrm{SD}=0.53,52 \%\right.$ male $)$. Results: When examining the direct relationship between sleep and technology use, cross-lagged panel models showed that time spent using technology predicted shorter sleep duration and greater daytime sleepiness in adolescence, and evening diurnal preference and shorter sleep duration contributed to increased technology use over time. The relationship between technology use and sleep duration was bi-directional. Time spent using technology and adolescent sleep predicted, yet were not predicted by, parental control of technology use. Conclusions: While normative changes in sleep (e.g., increased eveningness) may promote increased technology use, technology use may further impinge upon sleep. Results suggest it may be pertinent to instead find creative ways in which adolescents themselves can mitigate their risk of inadequate sleep.
\end{abstract}

Keywords: Media, parenting, sleep duration, eveningness, daytime sleepiness. 


\section{Introduction}

In the transition from childhood to adolescence, two notable changes in sleep occur. Young people develop an increasingly evening diurnal preference (i.e., being most mentally and physically alert in the evening) and sleep duration declines. More than half of adolescents obtain insufficient (<8hr) sleep on school nights (Gradisar, Gardner, \& Dohnt, 2011), resulting in daytime sleepiness, impaired physical and psychosocial health, reduced academic performance and increased risk-taking (Shochat, Cohen-Zion, \& Tzischinsky, 2014). Leaders in the field have recently called for longitudinal research aiming to identify risk and protective factors for insufficient sleep in adolescence (Tarokh, Short, Crowley, FontanellazCastiglione, \& Carskadon, 2019). Biological factors contributing to increased eveningness and reduced sleep duration in adolescence are relatively well understood. For example, a delay in circadian timing and slower build-up of homeostatic sleep pressure (i.e., sleepiness) occur alongside pubertal maturation, contributing to later sleep timing (Tarokh et al., 2019). Further, early school start times work against adolescent biology curtailing sleep duration on weekdays (Crowley, Wolfson, Tarokh, \& Carskadon, 2018). The updated "perfect storm" model of adolescent sleep proposes that psychosocial pressures interact with bio-regulatory processes to contribute to short and ill-timed sleep in adolescence (Crowley et al., 2018). Given that psychosocial factors are more easily modifiable than biological contributors, psychosocial risk/protective factors warrant further attention.

Adolescents today are reporting even shorter sleep durations relative to their predecessors (Keyes, Maslowsky, Hamilton, \& Schulenberg, 2015; Matricciani, Olds, \& Petkov, 2012). Technology use has also burgeoned over recent decades (Borlase, Gander, \& Gibson, 2013) and is one factor that may contribute to the trend in worsening adolescent sleep. There are many pathways by which technology use may impact adolescent sleep. In one of the earliest reviews of the paediatric sleep and technology use literature, Cain and 
Gradisar (2010) suggested that technology use may disrupt sleep in three ways: i) by displacing sleep and other sleep promoting activities (e.g., sleep hygiene), ii) by causing physiological arousal, which interferes with sleep and iii) by exposing people to bright light which may delay melatonin (the hormone that promotes sleep) onset, and thus sleep onset. All of these mechanisms may contribute to the trend towards increasing eveningness, curtailed school day sleep duration and greater daytime sleepiness in adolescence.

Indeed, there is substantial cross-sectional evidence which suggests an association between technology use and eveningness, sleep duration and daytime sleepiness. For example, computer, mobile phone, TV, and electronic display use are all cross-sectionally related to eveningness in adolescents and young adults (Fossum, Nordnes, Storemark, Bjorvatn, \& Pallesen, 2014; Kauderer \& Randler, 2013; Shimura et al., 2018). Further, mobile phone use and computer use are associated with shorter sleep duration; and mobile phone, internet and social media use, as well as video gaming, are associated with daytime sleepiness (Bartel et al., 2016; Carter, Rees, Hale, Bhattacharjee, \& Paradkar, 2016; Hale \& Guan, 2015; Johansson, Petrisko, \& Chasens, 2016; Polos et al., 2015).

Although there is consistent evidence for a cross-sectional association between technology use and adolescent sleep, longitudinal data are less common and findings about the direction of effects are mixed. One longitudinal study with pre-adolescents (aged 10-11 years) found both computer and television use predicted later bedtimes and shorter sleep duration on school nights 18-months later (Nuutinen, Ray, \& Roos, 2013). Patte and colleagues (2018) also investigated the relationship from technology use to subsequent sleep in adolescents in Grades 9-12 ( 14-17 years). They measured a wider array of technology, but did not find a prospective relationship between TV, video gaming, telephone, internet or social networking use and insufficient sleep duration (Patte et al., 2018). Differences in findings may be partly attributable to age differences between the samples. In both studies, 
the relationships from sleep to subsequent technology use were not investigated, which is a limitation given there is increasing evidence that young people may turn to technology as an aid when they have difficulty sleeping (Eggermont \& Van den Bulck, 2006; Tavernier \& Willoughby, 2014).

Three longitudinal studies have investigated bi-directionality between technology use and adolescent sleep duration or daytime sleepiness. Mazzer and colleagues (2018) found support for bi-directionality between time spent using technology (TV, computer and smartphone use etc.) and sleep duration across one year in Grade 8 and 9 students ( 14-16 years). The second longitudinal study with adolescents (aged 10-17 years) found baseline computer/ internet use, but not TV or mobile phone use, predicted greater bedtime problems (possibly indicative of eveningness) and daytime sleepiness 12-months later (Poulain et al., 2019). Inversely, daytime sleepiness predicted increased TV use one year later, yet no other longitudinal relationships from sleep (bedtime problems, sleep behaviour problems) to technology use (computer/internet, mobile phone) emerged (Poulain et al., 2019). Finally, in a specific investigation of social media use, van der Schuur and colleagues (2019) did not find any longitudinal or bidirectional relationships between social media use and daytime sleepiness. Overall, longitudinal evidence that technology use may affect adolescent sleep, and that adolescent sleep problems may also affect technology use over time remains inconsistent. Methodological differences between studies (e.g., focus on different sleep variables, different measures of technology use, samples heterogeneous in age, relatively short follow-up) may explain inconsistent findings, therefore the current study aims to address some of these concerns to better understand the association between technology use and adolescent sleep. 


\subsection{Parental Control of Technology Use and Adolescent Sleep.}

Parents are ideally placed to moderate adolescent technology use, particularly early in the adolescent period. Parental limit setting may minimise the effect that technology use has on sleep, and thus, may protect adolescents from shifting towards an evening diurnal preference, inadequate sleep duration and daytime somnolence. Cross-sectionally, adolescents with an evening diurnal preference report decreased parental monitoring (e.g., over duration and content of TV watched) (Gau et al., 2007), and the absence of parental rules about television, computer and video game use has been associated with later bedtimes (Pieters et al., 2014). Similarly, children (aged 6-17 years) of parents who had rules about television stop time, slept longer than children who did not have clear rules (Buxton et al., 2015). Longitudinally, parental monitoring predicts both less screen time and longer sleep duration (Gentile, Reimer, Nathanson, Walsh, \& Eisenmann, 2014; Maume, 2013). However, since both of these studies used a two-wave longitudinal design, and did not adequately control for stability in variables over time, it is not yet clear whether time spent using technology mediates the relationship between parental control of technology use and adolescent sleep. Further, the effects of parental control over technology on eveningness and daytime sleepiness are not yet known.

\subsection{Present Study}

Few longitudinal studies have investigated bi-directional associations between technology use and adolescent sleep, and findings to date have been mixed, likely due to methodological differences between studies (e.g., measurement of sleep and technology, sample, number and lag between follow-ups). Therefore, additional studies measuring sleep and technology more comprehensively, in an age homogenous sample, with longer followups, are needed to better understand this association. No longitudinal studies have explicitly 
measured morningess/eveningness diurnal preference to date, and prior research has suggested the need for more comprehensive measurement of adolescent sleep (Patte et al., 2018). As such, the first aim of the current study was to investigate longitudinal bi-directional associations between time spent using technology (watching TV, playing video games, browsing the internet and social media) and morning/eveningness preference, school night sleep duration and daytime sleepiness in a homogenous sample of early adolescents, over 3 time waves, 2 years apart. Further, the field is moving towards examining factors that may mitigate risks to adolescent sleep, yet no studies have adequately investigated the relationship between parental control of technology and adolescent sleep, nor whether time spent using technology mediates the relationship between parental control of technology and adolescent sleep. As such, this was the second aim of the present study.

In the absence of clear findings to date, and based on the demonstrated associations between variables, it was hypothesised that more time spent using technology would predict worse adolescent sleep (evening diurnal reference, shorter school night sleep duration, higher daytime sleepiness) over time, and inversely, that worse adolescent sleep would predict more time spent using technology. Next, it was expected that parental control of technology use would predict better adolescent sleep, and that this relationship would be mediated by (less) time spent using technology.

\section{Method}

\subsection{Participants}

A total of $528\left(M_{\text {age }}=11.18, \mathrm{SD}=0.56\right.$, range $=10-12,51 \%$ male $)$ early adolescents and their parent/ primary caregiver ( $96 \%$ mothers) commenced the study in Wave 1 . Of these participants, $502\left(M_{a g e}=12.19, \mathrm{SD}=0.53,52 \%\right.$ male $)$ completed the relevant measures again in Wave 2, and $478\left(M_{\text {age }}=13.19, \mathrm{SD}=0.53,52 \%\right.$ male $)$ completed the same measures in 
Wave 3, with each wave 1-year apart. Approximately $90 \%$ of participants were born in Australia (3\% United Kingdom, 1.5\% United States, 0.8\% New Zealand, 0.6\% South Africa, $3.5 \%$ other), with $82 \%$ reporting having white European origins (6.6\% Asian, $1.5 \%$ Middle Eastern, 10\% other). Most (96.4\%) participants spoke English as their first language at home (1.1\% Mandarin, $0.2 \%$ Italian, $2.3 \%$ other), and approximately $80 \%$ of families reported being from middle to high income households. Participants were recruited from the general public via advertisements placed in schools, sporting clubs and medical centers in Sydney, Australia.

\subsection{Procedures}

The current study was part of a larger longitudinal cohort study, the Risks to Adolescent Wellbeing (RAW) Project, which was approved by the Macquarie University Human Research Ethics Committee. Informed consent was obtained from all parents and assent was obtained from early adolescents. Adolescents also re-assented in each year of the study prior to the collection of their data. At each wave of data collection, parent-child dyads completed an online questionnaire via Qualtrics (Qualtrics, Provo, UT). Each family was given AUD\$100 per year for participating in the RAW Project, along with a small gift bag for each child to the value of approximately AUD\$10-\$15.

\subsection{Measures}

\subsubsection{Time Spent Using Technology}

Adolescents were asked how long they spend using four forms of technology (i.e., watching television, playing video games, browsing the internet (excluding social media) and browsing social media), on school days, with responses indicated on an 11-point scale $(0=$

No time, $10=10-12$ hours or more). A technology use composite score was calculated by averaging items (range 0-10), with higher scores indicating longer time spent using 
technology. Relationships between individual technology types, sleep and parental control were explored and are reported in a supplementary file (Tables S3-18). The reliability of the technology use scale was acceptable at Wave $1(\alpha=0.74)$, Wave $2(\alpha=0.73)$ and Wave $3(\alpha$ $=0.68)$.

\subsubsection{Parental Control of Technology}

Parents reported their control over their adolescent's technology use by indicating how much control they have over the amount of time their child spends on the same four technological devices/types (television, game console, internet, social media). Parents responded on a 4-point scale ( $0=$ No control (my child decides), $1=\mathrm{A}$ little control, $2=$ Moderate control, 3 = A lot of control (I set clear rules for my child). A parental control composite score was calculated by averaging items (range: 0-3), with higher scores indicating greater parental control over technology use. The reliability of the parental control over technology use scale was acceptable at Wave $1(\alpha=0.88)$, Wave $2(\alpha=0.87)$ and Wave $3(\alpha$ $=0.88)$.

\subsubsection{Morning/ Eveningness Preference}

Adolescent's self-reported diurnal preference was measured using the 10-item Children's Morningness-Eveningness Scale (MESC) (Carskadon, Seifer, \& Acebo, 1991). Items are rated on a 4-point scale, with total scores ranging from 10-43. Lower scores indicate evening preference, while higher scores indicate morningness. Whilst continuous scores were used in analyses, for descriptive purposes, total scores from 10-20 indicate evening diurnal preference, 21-27 intermediate diurnal preference and 28-43 morning diurnal preference. Reliability of the morningness-eveningness scale was good at Wave $1(\alpha=0.79)$, Wave $2(\alpha=0.81)$ and Wave $3(\alpha=0.83)$, in line with past research $(\alpha=0.73)$ (Giannotti, Cortesi, Sebastiani, \& Ottaviano, 2002). 


\subsubsection{School Night Sleep Duration}

Adolescent school night sleep duration was assessed and analysed separately by both adolescent- and parent-report, using a single item ("How many hours sleep do you usually get each night on a school night?”, "On average, how many hours sleep does your child get each night on a school night?"). Respondents indicated the average number of hours on a scale from 0-12. Relationships between parent-reported sleep duration, parental control of technology and time spent using technology were explored and are reported in a supplementary file (Table S1, Figure S1 and Table S2).

\subsubsection{Daytime Sleepiness}

Daytime sleepiness was measured using the 8 item Pediatric Daytime Sleepiness Scale (PDSS) (Drake et al., 2003). Adolescents reported their level of daytime sleepiness (e.g., "How often do you fall asleep or feel drowsy in class?") on a 5-point scale ( $0=$ Never to $4=$ Always). Total scores range from 0-32, with higher scores indicating greater daytime sleepiness. In line with past research $(\alpha=0.80)$, reliability of the daytime sleepiness scale was acceptable across all waves (Wave $1 \alpha=0.78$; Wave $2 \alpha=0.81$; Wave $3 \alpha=0.83$ ) (Drake et al., 2003).

\subsection{Statistical Analysis}

Data aggregation and preliminary analyses were undertaken using SPSS. Repeated measures ANOVAs were used to assess for change in variables over time. Longitudinal cross-lagged panel analyses were undertaken with MPlus version 8.5 (Muthén \& Muthén, 2015). To address the first aim, models were specified to examine the direct relationship between time spent using technology and adolescent sleep, with separate models for each sleep measure (i.e., school night sleep duration, morning/eveningness preference, daytime sleepiness). To address the second aim of the study, additional models were specified to 
examine the bi-directional relationships between time spent on technology, parental control of technology use and adolescent sleep, with separate models for each sleep measure (see Figure 1 for a schematic representation of the models). In all models, autoregressive paths (i.e., controlling for baseline levels) and cross-lagged paths between technology use, parental control and sleep variables were specified, and equality constraints were placed on all autoregressive and cross-lagged paths over time. Standardized beta coefficients are reported to allow for comparisons of the relative strength of longitudinal associations.

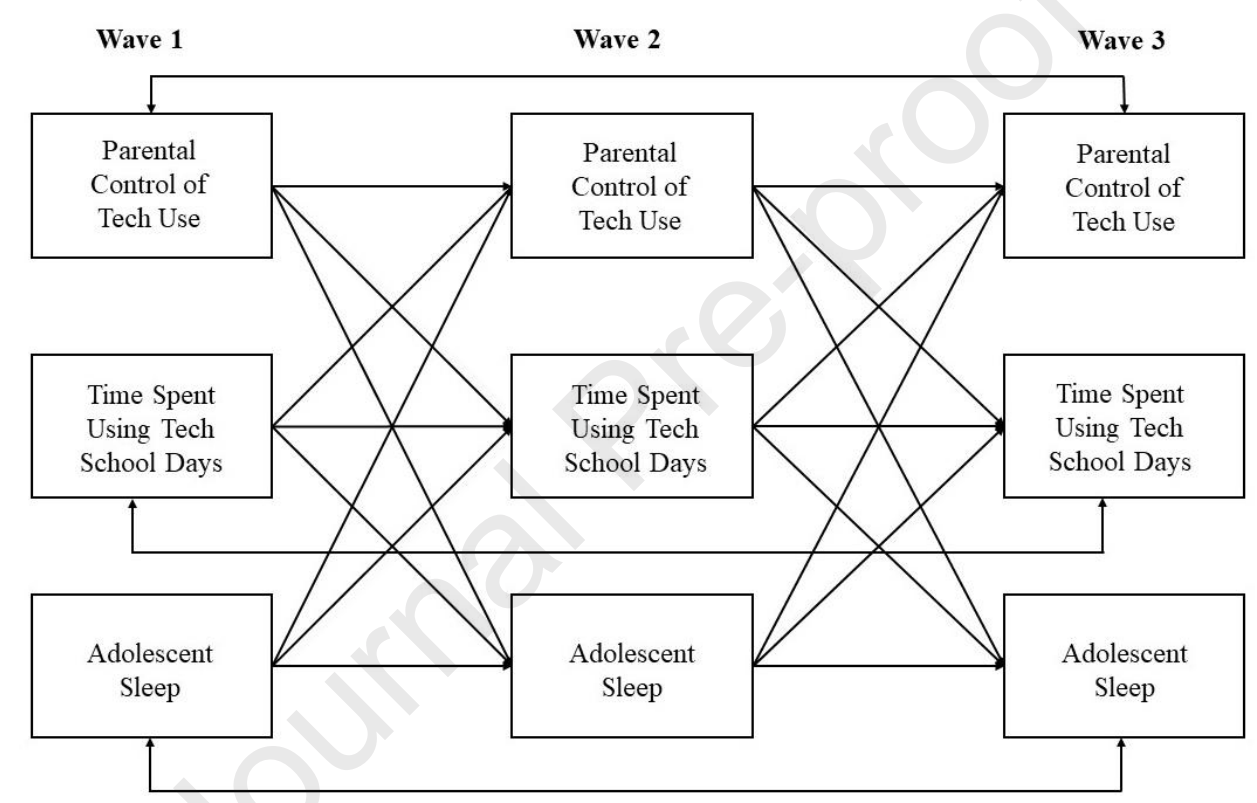

Figure 1. Schematic illustrating the autoregressive and cross-lagged paths between time spent using technology, parental control of technology and adolescent sleep. Although not depicted in this figure to avoid visual overcrowding, all variables were regressed onto sex, to control for the effects of sex.

Sex was statistically controlled in all models. Moderation by sex was explored in a multi-group analysis framework where the model was estimated separately for boys and girls, and then with all regression paths constrained to equality between the two groups. As per the Satorra-Bentler scaled chi-square difference test, significant differences in model fit between the unconstrained and constrained models indicated moderation (Satorra, 2000). Constraining 
the paths to equality did not adversely affect model fit for morning/ eveningness $\left(X^{2}(21)=\right.$ $21.85, p=.408)$, adolescent reported sleep duration $\left(\mathrm{X}^{2}(21)=23.86, p=.300\right)$, or daytime sleepiness $\left(\mathrm{X}^{2}(21)=30.89, p=.076\right)$, indicating that the strength of the autoregressive and cross-lagged paths did not significantly vary by sex. As such, only models controlling for sex are presented.

There were between $0.6-1.1 \%$ missing data for any given variable in Wave 1, except school night sleep duration (5.1\% adolescent-report) which was slightly higher since the first 24 participants were not presented this question in Wave 1. There were between 5.5-6.6\% missing data for any given variable in Wave 2, and between 10.2-10.9\% missing data in Wave 3. However, data were missing completely at random (Little's Missing Completely at Random test, $\mathrm{p}>0.05)$. Missing data were handled using full information maximum likelihood estimation (FIML) in cross-lagged models. As some variables were significantly skewed (e.g., morning/ eveningness), Spearman's Rho and the MLR robust maximum likelihood estimator were used to estimate descriptive and cross-lagged analyses, respectively. Given the large number of comparisons in the current paper, significance levels were adjusted to account for a paper-wide $5 \%$ false discovery rate using the Benjamini-Hochberg procedure (Benjamini \& Hochberg, 1995). The first raw p-value to exceed the Benjamini-Hochberg adjusted $p$-value corresponding to a false discovery rate of $5 \%$ was $p \leq .034$. Although beyond the scope of the present study, models were also run for each technology type separately, with these models presented in a supplementary file. 


\section{Results}

\subsection{Preliminary Analyses}

Descriptive statistics and results from ANOVAs relating to technology use, parental control and sleep are presented in Table 1. The repeated measures ANOVAs revealed a significant main effect of time for time spent using technology, parental control of technology, adolescent-reported sleep duration, morning/ eveningness and daytime sleepiness. Effect sizes $(d)$ calculated from Wave 1 to Wave 2 and from Wave 2 to Wave 3 revealed small increases in overall time spent using technology each year. Small reductions in parental control of technology also occurred. In relation to sleep, small-to-moderate decreases in adolescent-reported school night sleep duration were observed, small shifts away from a morning diurnal preference occurred over time, and very small increases in daytime sleepiness were seen. In Wave 1, 79\% of participants were morning-types, $19 \%$ intermediatetypes and 2\% evening-types. In Wave 2, 75\% were morning-types, $22 \%$ intermediate-types and 3\% evening-types. In Wave 3,66\% were morning-types, $29 \%$ intermediate-types and 5\% evening-types. 
Table 1.

Descriptive statistics for composite technology use and sleep variables in Wave 1, Wave 2 and Wave 3, and inferential statistics for repeated measures ANOVAs, testing changes in variables over time.

\begin{tabular}{|c|c|c|c|c|c|c|c|c|}
\hline & & $\begin{array}{c}\text { Wave 1 } \\
(\mathbf{N}=\mathbf{5 2 8}) \\
\text { Mean }(S D) \\
\text { Range }\end{array}$ & $\begin{array}{c}\text { Wave 2 } \\
(\mathbf{N}=\mathbf{5 0 2}) \\
\text { Mean }(S D) \\
\text { Range }\end{array}$ & $\begin{array}{c}\text { Wave } 3 \\
(\mathbf{N}=478) \\
\text { Mean }(S D) \\
\text { Range }\end{array}$ & $F$ & $p$ & $\begin{array}{l}d^{d} \\
\mathrm{~W} 1 / \\
\mathrm{W} 2\end{array}$ & $\begin{array}{l}\text { W2/ } \\
\text { W3 }\end{array}$ \\
\hline & Age & $\begin{array}{c}11.18(0.56) \\
10-12\end{array}$ & $\begin{array}{c}12.19(0.53) \\
11-13\end{array}$ & $\begin{array}{c}13.19(0.53) \\
12-14\end{array}$ & & & & \\
\hline \multirow{2}{*}{ 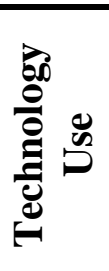 } & $\begin{array}{l}\text { Time Spent using } \\
\text { Technology (Sch) }\end{array}$ & $\begin{array}{c}2.47(1.30) \\
0.00-7.75\end{array}$ & $\begin{array}{c}2.74(1.34) \\
0.00-7.75\end{array}$ & $\begin{array}{c}3.11(1.33) \\
0.00-8.00\end{array}$ & 62.01 & $<.001$ & 0.20 & 0.28 \\
\hline & $\begin{array}{l}\text { Parental Control of } \\
\text { Technology Use }\end{array}$ & $\begin{array}{c}2.46(0.60) \\
0.00-3.00\end{array}$ & $\begin{array}{c}2.24(0.64) \\
0.00-3.00\end{array}$ & $\begin{array}{c}2.00(0.75) \\
0.00-3.00\end{array}$ & 118.65 & $<.001$ & 0.35 & 0.34 \\
\hline \multirow{3}{*}{$\frac{2}{\text { के }}$} & $\begin{array}{l}\text { Sleep Duration (Sch, } \\
\text { Adolescent-Report) }\end{array}$ & $\begin{array}{c}9.30(1.18) \\
3-12\end{array}$ & $\begin{array}{c}8.84(1.13) \\
4-12\end{array}$ & $\begin{array}{c}8.43(1.14) \\
3-11\end{array}$ & 91.74 & $<.001$ & 0.40 & 0.36 \\
\hline & Morning/ Eveningness & $\begin{array}{l}31.38(5.02) \\
14.00-43.00\end{array}$ & $\begin{array}{l}30.84(5.14) \\
13.00-43.00\end{array}$ & $\begin{array}{l}29.66(5.38) \\
12.00-42.00\end{array}$ & 38.31 & $<.001$ & 0.11 & 0.22 \\
\hline & Daytime Sleepiness & $\begin{array}{c}10.95(5.62) \\
0-28\end{array}$ & $\begin{array}{c}10.86(5.85) \\
0-30\end{array}$ & $\begin{array}{c}11.76(6.26) \\
0-31\end{array}$ & 6.42 & .002 & 0.02 & 0.15 \\
\hline
\end{tabular}

Note: Sch = School Day/Night. 
Table 2 shows spearman rho correlations between composite technology use, parental control and adolescent sleep. Correlations suggest small-to-moderate associations between overall time spent on technology, parental control of technology use and adolescent sleep, whereby more time spent using technology is associated with worse adolescent sleep and greater parental control of technology use is associated with better adolescent sleep and less time spent using technology. 
Table 2.

Spearman rho correlations between school day technology use, parental control of technology use and adolescent sleep.

\begin{tabular}{|c|c|c|c|c|c|c|c|c|c|c|c|c|c|c|c|c|}
\hline & \multicolumn{5}{|c|}{ Wave 1} & \multicolumn{5}{|c|}{ Wave 2} & \multicolumn{5}{|c|}{ Wave 3} \\
\hline & & \multicolumn{2}{|c|}{ Technology } & \multicolumn{3}{|c|}{ Sleep } & \multicolumn{2}{|c|}{ Technology } & \multicolumn{3}{|c|}{ Sleep } & \multicolumn{2}{|c|}{ Technology } & \multicolumn{3}{|c|}{ Sleep } \\
\hline & & $\mathrm{TU}$ & PCT & SDA & $\mathrm{M} / \mathrm{E}$ & DS & $\mathrm{TU}$ & PCT & SDA & $\mathrm{M} / \mathrm{E}$ & $\mathrm{DS}$ & $\mathrm{TU}$ & PCT & SDA & $\mathrm{M} / \mathrm{E}$ & DS \\
\hline \multirow{5}{*}{$\begin{array}{l}\bar{D} \\
\vec{z} \\
\vec{z}\end{array}$} & TU & - & -0.28 & -0.17 & -0.26 & 0.21 & 0.57 & -0.29 & -0.18 & -0.23 & 0.18 & 0.51 & -0.23 & -0.12 & -0.21 & 0.09 \\
\hline & PCT & & - & 0.19 & 0.15 & -0.13 & -0.23 & 0.57 & 0.09 & 0.17 & -0.14 & -0.23 & 0.52 & 0.16 & 0.20 & -0.13 \\
\hline & SDA & & & - & 0.24 & -0.27 & -0.14 & 0.19 & 0.40 & 0.25 & -0.20 & -0.14 & 0.12 & 0.29 & 0.18 & -0.19 \\
\hline & $\mathrm{M} / \mathrm{E}$ & & & & - & -0.64 & -0.24 & 0.20 & 0.20 & 0.65 & -0.42 & -0.30 & 0.18 & 0.18 & 0.58 & -0.36 \\
\hline & DS & & & & & - & 0.20 & -0.18 & -0.17 & -0.46 & 0.54 & 0.20 & -0.16 & -0.19 & -0.44 & 0.50 \\
\hline \multirow{5}{*}{ 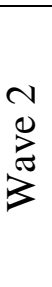 } & $\mathrm{TU}$ & & & & & & - & -0.23 & -0.24 & -0.28 & 0.22 & 0.58 & -0.25 & -0.14 & -0.21 & 0.18 \\
\hline & PCT & & & & & & & $0-$ & 0.17 & 0.19 & -0.18 & -0.19 & 0.60 & 0.16 & 0.17 & -0.18 \\
\hline & SDA & & & & & & 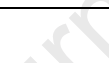 & & - & 0.26 & -0.25 & -0.18 & 0.13 & 0.43 & 0.24 & -0.19 \\
\hline & $\mathrm{M} / \mathrm{E}$ & & & & & & & & & - & -0.59 & -0.24 & 0.19 & 0.25 & 0.69 & -0.45 \\
\hline & DS & & & & & $N$ & 8 & & & & - & 0.17 & -0.18 & -0.23 & -0.48 & 0.58 \\
\hline \multirow{5}{*}{ 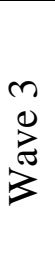 } & $\mathrm{TU}$ & & & & & 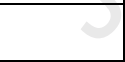 & & & & & & - & -0.19 & -0.18 & -0.31 & 0.21 \\
\hline & PCT & & & & & & & & & & & & - & 0.22 & -0.25 & -0.20 \\
\hline & SDA & & & & & & & & & & & & & - & 0.31 & -0.35 \\
\hline & $\mathrm{M} / \mathrm{E}$ & & & & & & & & & & & & & & - & -0.62 \\
\hline & DS & & & & & & & & & & & & & & & - \\
\hline
\end{tabular}

Note. Statistically significant correlations are denoted in bold font $(\mathrm{p} \leq .034)$. TU $=$ time spent using technology on school days, PCT $=$ parental control of technology use, $\mathrm{SDA}=$ adolescent-reported school night sleep duration, $\mathrm{M} / \mathrm{E}=$ morning/eveningness preference, $\mathrm{DS}=\mathrm{daytime}$ sleepiness. 


\subsection{Longitudinal Cross-Lagged Models}

\subsubsection{Morning/Eveningness Diurnal Preference}

Table 3 provides standardised beta coefficients for all autoregressive and cross-lagged paths in the model investigating the direct relationship between technology use and morning/eveningness diurnal preference. Greater evening diurnal preference (lower scores indicate increased evening preference) predicted more time spent using technology from Wave 1 to Wave 2, and from Wave 2 to Wave 3, yet technology use did not significantly predict morning/eveningness preference.

Table 3.

Standardised Beta coefficients and 95\% confidence intervals for all autoregressive and cross-lagged paths between school day technology use and morning/eveningness in Wave 1,

Wave 2 and Wave 3, controlling for sex.

\section{Autoregressive Paths}

\begin{tabular}{cccccc}
\hline Wave 1 & Wave 2 & $\boldsymbol{\beta}$ & SE & $\mathbf{9 5 \%} \boldsymbol{C I}$ & $\boldsymbol{p}$ \\
\hline Technology Use & Technology Use & 0.48 & 0.03 & $0.43-0.54$ & $<.001$ \\
\hline Morning/Eveningness & Morning/Eveningness & 0.64 & 0.03 & $0.60-0.68$ & $<.001$ \\
\hline Wave 2 & Wave 3 & $\boldsymbol{\beta}$ & $\mathbf{S E}$ & $\mathbf{9 5 \%} \boldsymbol{C I}$ & $\boldsymbol{p}$ \\
\hline Technology Use & Technology Use & 0.48 & 0.03 & $0.43-0.54$ & $<.001$ \\
\hline Morning/Eveningness & Morning/Eveningness & 0.61 & 0.03 & $0.56-0.66$ & $<.001$ \\
\hline Wave 1 & Wave 3 & $\boldsymbol{\beta}$ & SE & $\mathbf{9 5 \%} \boldsymbol{C I}$ & $\boldsymbol{p}$ \\
\hline Technology Use & Technology Use & 0.22 & 0.04 & $0.15-0.28$ & $<.001$ \\
\hline Morning/Eveningness & Morning/Eveningness & 0.15 & 0.04 & $0.09-0.21$ & $<.001$ \\
\hline Wave 1 & Cross-lagged Paths & & & \\
\hline Technology Use & Morning/Eveningness & -0.05 & 0.03 & $-0.09-0.006$ & 0.058 \\
\hline Morning/Eveningness & Technology Use & -0.10 & 0.03 & $-0.15--0.05$ & 0.002 \\
\hline Wave 2 & Wave 3 & $\boldsymbol{\beta}$ & $\mathbf{S E}$ & $\mathbf{9 5 \%} \boldsymbol{C I}$ & $\boldsymbol{p}$ \\
\hline Technology Use & Morning/Eveningness & -0.05 & 0.02 & $-0.08-0.006$ & 0.055 \\
\hline Morning/Eveningness & Technology Use & -0.10 & 0.03 & $-0.15--0.05$ & 0.002 \\
\hline
\end{tabular}


Note: Model Fit: $X^{2}(N=494)=30.68, d f=11, \mathrm{CFI}=0.98, \mathrm{TLI}=0.97, \mathrm{RMSEA}=0.060$.

Adjusted significance levels $=\mathrm{p} \leq .034$.

Figure 2 depicts the statistically significant paths in the cross-lagged model investigating the relationship between time spent using technology on school days, parental control of technology use and morning/eveningness diurnal preference. Table 4 displays the standardised beta coefficients for all autoregressive and cross-lagged paths. As per the previous model, greater evening diurnal preference (lower scores indicate increased evening preference) predicted more time spent using technology from Wave 1 to Wave 2, and from Wave 2 to Wave 3. Longer time spent using technology and greater eveningness predicted less parental control over technology use from Wave 1 to Wave 2, and from Wave 2 to Wave 3. No other significant cross-lagged paths emerged. Given the significant paths between Wave 1 morning/eveningness preference, Wave 2 time spent using technology on school days (possible mediator) and Wave 3 parental control of technology use, mediation was assessed, and the indirect effect was significant $(\beta=.001, \mathrm{SE}=.001, p=.025)$.

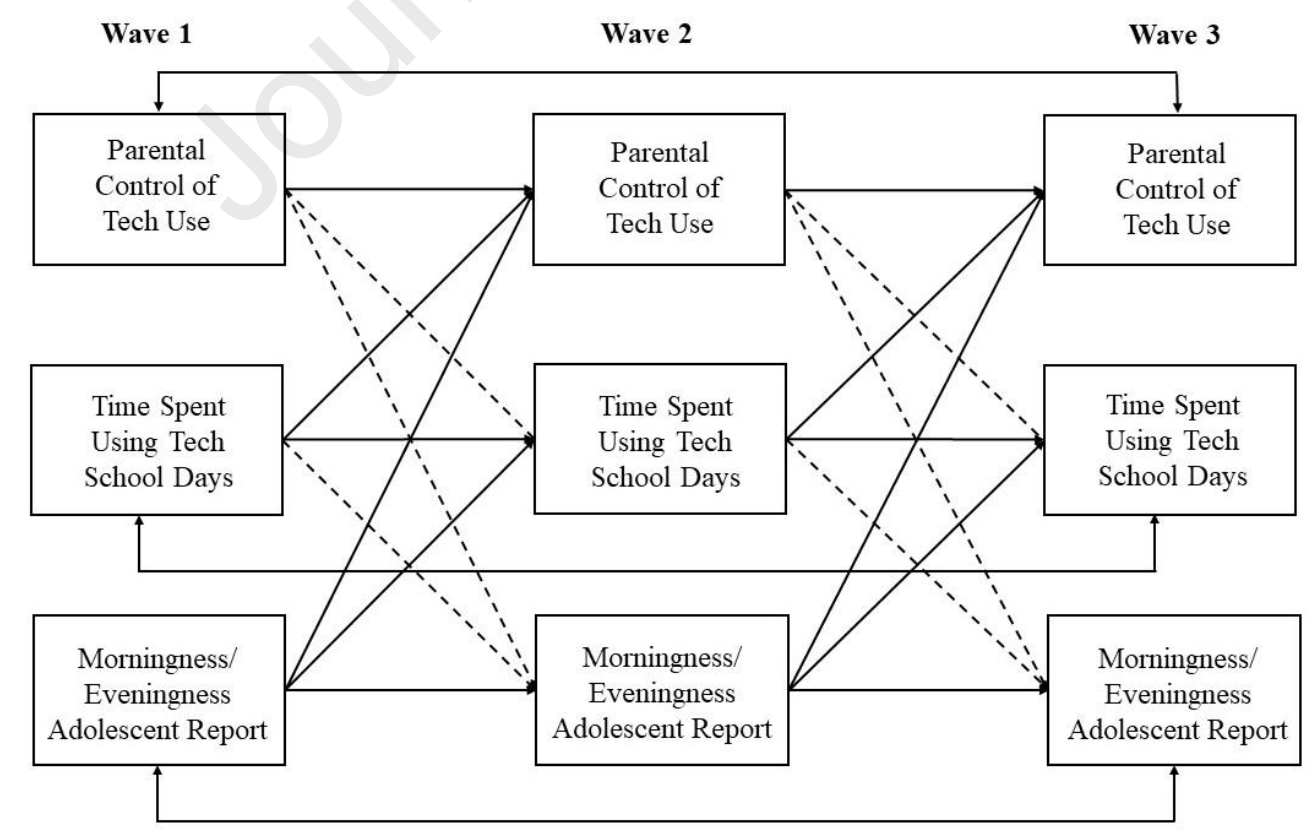

Figure 2. Schematic illustrating the statistically significant relationships between technology use on school days, parental control of technology use and adolescent-reported morning/ 
eveningness diurnal preference at Wave 1, Wave 2 and Wave 3. Solid lines $=$ significant paths, dashed lines $=$ non-significant paths.

Table 4.

Standardised Beta coefficients and 95\% confidence intervals for all autoregressive and cross-lagged paths between school day technology use, parental control of technology use, and morning/eveningness in Wave 1, Wave 2 and Wave 3, controlling for sex.

\section{Autoregressive Paths}

\begin{tabular}{|c|c|c|c|c|c|}
\hline Wave 1 & Wave 2 & $\boldsymbol{\beta}$ & SE & $95 \% C I$ & $p$ \\
\hline Technology Use & Technology Use & 0.47 & 0.03 & $0.41-0.52$ & $<.001$ \\
\hline Parental Control & Parental Control & 0.53 & 0.03 & $0.48-0.60$ & $<.001$ \\
\hline Morning/Eveningness & Morning/Eveningness & 0.64 & 0.03 & $0.60-0.69$ & $<.001$ \\
\hline Wave 2 & Wave 3 & $\boldsymbol{\beta}$ & SE & $95 \% C I$ & $p$ \\
\hline Technology Use & Technology Use & 0.47 & 0.03 & $0.42-0.52$ & $<.001$ \\
\hline Parental Control & Parental Control & 0.49 & 0.04 & $0.43-0.55$ & $<.001$ \\
\hline Morning/Eveningness & Morning/Eveningness & 0.62 & 0.03 & $0.56-0.67$ & $<.001$ \\
\hline Wave 1 & Wave 3 & $\boldsymbol{\beta}$ & SE & $95 \% C I$ & $p$ \\
\hline Technology Use & Technology Use & 0.21 & 0.04 & $0.14-0.28$ & $<.001$ \\
\hline Parental Control & Parental Control & 0.21 & 0.04 & $0.14-0.27$ & $<.001$ \\
\hline Morning/Eveningness & Morning/Eveningness & 0.15 & 0.04 & $0.08-0.21$ & $<.001$ \\
\hline \multicolumn{6}{|c|}{ Cross-lagged Paths } \\
\hline Wave 1 & Wave 2 & $\beta$ & SE & $95 \% C I$ & $p$ \\
\hline Technology Use & Parental Control & -0.12 & 0.03 & $-0.17-0.06$ & $<0.001$ \\
\hline Technology Use & Morning/Eveningness & -0.03 & 0.03 & $-0.08-0.01$ & 0.214 \\
\hline Parental Control & Technology Use & -0.04 & 0.02 & $-0.08-0.008$ & 0.045 \\
\hline Parental Control & Morning/Eveningness & -0.006 & 0.02 & $-0.04-0.03$ & 0.782 \\
\hline Morning/Eveningness & Technology Use & -0.09 & 0.03 & $-0.14--0.04$ & 0.005 \\
\hline Morning/Eveningness & Parental Control & 0.08 & 0.03 & $0.03-0.13$ & 0.006 \\
\hline Wave 2 & Wave 3 & $\beta$ & SE & $95 \% C I$ & $p$ \\
\hline Technology Use & Parental Control & -0.10 & 0.03 & $-0.14--0.06$ & $<0.001$ \\
\hline Technology Use & Morning/Eveningness & -0.03 & 0.03 & $-0.07-0.01$ & 0.211 \\
\hline Parental Control & Technology Use & -0.05 & 0.02 & $-0.08--0.008$ & 0.045 \\
\hline Parental Control & Morning/Eveningness & -0.006 & 0.02 & $-0.04-0.03$ & 0.782 \\
\hline Morning/Eveningness & Technology Use & -0.09 & 0.03 & $-0.14--0.04$ & 0.006 \\
\hline Morning/Eveningness & Parental Control & 0.07 & 0.03 & $0.03-0.11$ & 0.007 \\
\hline
\end{tabular}

Note: Model Fit: $X^{2}(N=492)=49.87, d f=24, \mathrm{CFI}=0.98, \mathrm{TLI}=0.97, \mathrm{RMSEA}=0.047$ 
Adjusted significance levels $=\mathrm{p} \leq .034$.

\subsubsection{Adolescent-reported School Night Sleep Duration}

Table 5 provides standardised beta coefficients for all autoregressive and cross-lagged paths in the model investigating the direct relationship between technology use and adolescent-reported school night sleep duration. There was evidence of bi-directionality with shorter sleep duration predicting more time spent using technology from Wave 1 to Wave 2 and from Wave 2 to Wave 3. More time spent using technology at Wave 1 and 2 also predicted shorter sleep duration in Wave 2 and 3, respectively.

Table 5.

Standardised Beta coefficients and 95\% confidence intervals for all autoregressive and cross-lagged paths between school day technology use and adolescent-reported school night sleep duration in Wave 1, Wave 2 and Wave 3, controlling for sex.

\section{Autoregressive Paths}

\begin{tabular}{cccccc}
\hline Wave 1 & Wave 2 & $\boldsymbol{\beta}$ & SE & $\mathbf{9 5 \%} \boldsymbol{C I}$ & $\boldsymbol{p}$ \\
\hline Technology Use & Technology Use & 0.49 & 0.03 & $0.43-0.54$ & $<.001$ \\
\hline Sleep Duration & Sleep Duration & 0.40 & 0.04 & $0.33-0.46$ & $<.001$ \\
\hline Wave 2 & Wave 3 & $\boldsymbol{\beta}$ & SE & $\mathbf{9 5 \%} \boldsymbol{C I}$ & $\boldsymbol{p}$ \\
\hline Technology Use & Technology Use & 0.49 & 0.03 & $0.43-0.54$ & $<.001$ \\
\hline Sleep Duration & Sleep Duration & 0.37 & 0.04 & $0.31-0.43$ & $<.001$ \\
\hline Wave 1 & Wave 3 & $\boldsymbol{\beta}$ & SE & $\mathbf{9 5 \%} \boldsymbol{C I}$ & $\boldsymbol{p}$ \\
\hline Technology Use & Technology Use & 0.23 & 0.04 & $0.16-0.30$ & $<.001$ \\
\hline Sleep Duration & Sleep Duration & 0.13 & 0.04 & $0.07-020$ & .001 \\
\hline Wave 1 & Cross-lagged Paths & & & \\
\hline Technology Use & Wave 2 & $\boldsymbol{\beta}$ & SE & $\mathbf{9 5 \%} \boldsymbol{C I}$ & $\boldsymbol{p}$ \\
\hline Sleep Duration & Sleep Duration & -0.12 & 0.04 & $-0.17--0.06$ & 0.001 \\
\hline Wave 2 & Wechnology Use & -0.07 & 0.03 & $-0.12-0.03$ & 0.011 \\
\hline Technology Use & Sleep Duration & -0.12 & 0.03 & $-0.17--0.06$ & 0.001 \\
\hline Sleep Duration & Technology Use & -0.07 & 0.03 & $-0.11-0.02$ & 0.012 \\
\hline Note: Model Fit: $X^{2}(N=474)=16.93, d f=11$, CFI $=0.99$, TLI $=0.98$, RMSEA $=0.034$ &
\end{tabular}


Adjusted significance levels $=\mathrm{p} \leq .034$.

Figure 3 depicts the statistically significant paths in the cross-lagged model investigating the relationship between time spent using technology on school days, parental control of technology use and adolescent-reported school night sleep duration. Table 6 displays the standardised beta coefficients for all autoregressive and cross-lagged paths. Longer time spent using technology on school days predicted shorter school night sleep duration from Wave 1 to Wave 2, and from Wave 2 to Wave 3. Longer time spent using technology also predicted less parental control of technology use from Wave 1 to Wave 2 , and from Wave 2 to Wave 3. No other significant cross-lagged paths emerged.

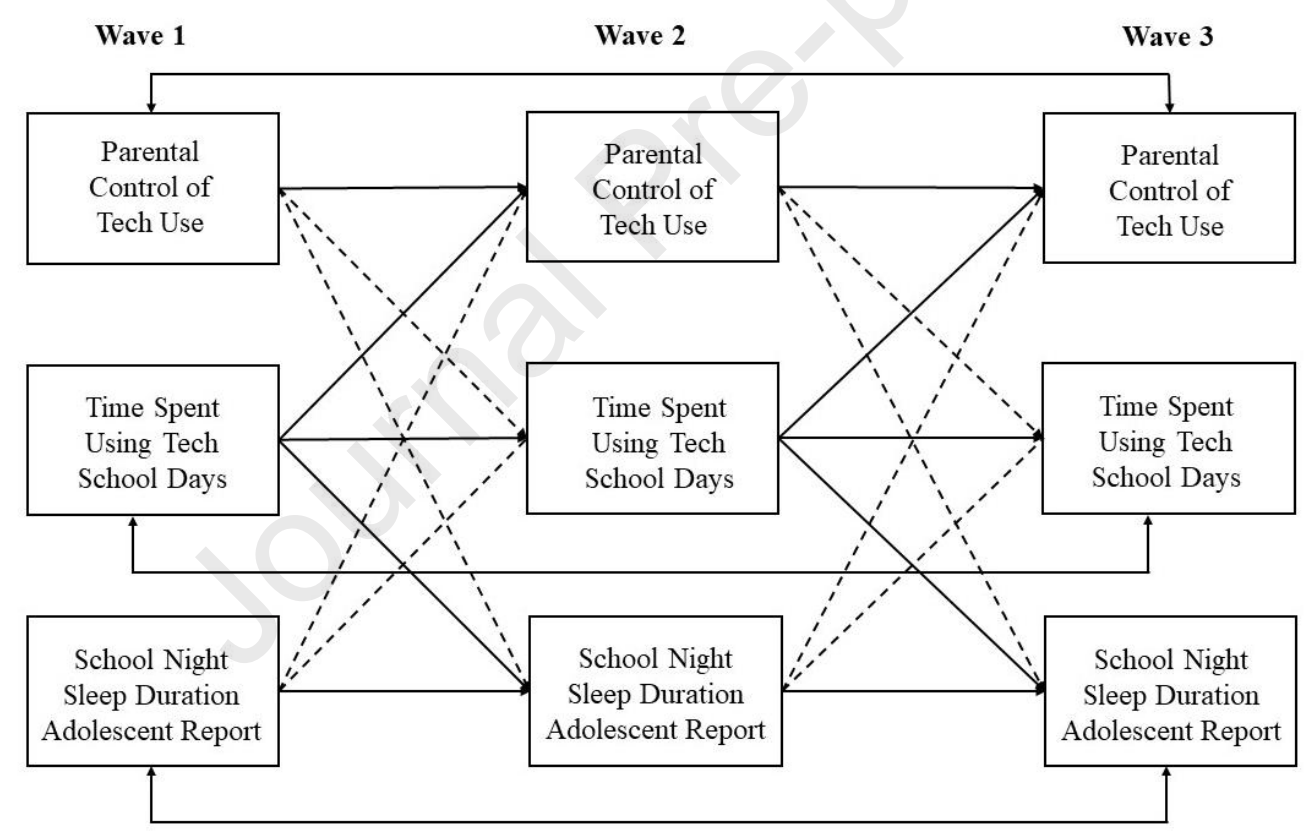

Figure 3. Schematic illustrating the statistically significant relationships between technology use on school days, parental control of technology use and adolescent-reported school night sleep duration at Wave 1, Wave 2 and Wave 3. Solid lines = significant paths, dashed lines = non-significant paths. 
Table 6.

Standardised Beta coefficients and 95\% confidence intervals for all autoregressive and cross-lagged paths between school day technology use, parental control of technology use, and adolescent-reported school night sleep duration in Wave 1, Wave 2 and Wave 3, controlling for sex.

\section{Autoregressive Paths}

\begin{tabular}{|c|c|c|c|c|c|}
\hline Wave 1 & Wave 2 & $\beta$ & SE & $95 \% C I$ & $p$ \\
\hline Technology Use & Technology Use & 0.48 & 0.04 & $0.42-0.53$ & $<.001$ \\
\hline Parental Control & Parental Control & 0.55 & 0.04 & $0.49-0.61$ & $<.001$ \\
\hline Sleep Duration & Sleep Duration & 0.41 & 0.04 & $0.34-0.47$ & $<.001$ \\
\hline Wave 2 & Wave 3 & $\boldsymbol{\beta}$ & $\mathbf{S E}$ & $95 \% C I$ & $p$ \\
\hline Technology Use & Technology Use & 0.48 & 0.03 & $0.42-0.53$ & $<.001$ \\
\hline Parental Control & Parental Control & 0.50 & 0.04 & $0.43-0.56$ & $<.001$ \\
\hline Sleep Duration & Sleep Duration & 0.38 & 0.04 & $0.34-0.47$ & $<.001$ \\
\hline Wave 1 & Wave 3 & $\boldsymbol{\beta}$ & SE & $95 \% C I$ & $p$ \\
\hline Technology Use & Technology Use & 0.22 & 0.04 & $0.15-0.29$ & $<.001$ \\
\hline Parental Control & Parental Control & 0.21 & 0.04 & $0.14-0.28$ & $<.001$ \\
\hline Sleep Duration & Sleep Duration & 0.14 & 0.04 & $0.07-021$ & .001 \\
\hline \multicolumn{6}{|c|}{ Cross-lagged Paths } \\
\hline Wave 1 & Wave 2 & $\boldsymbol{\beta}$ & SE & $95 \% C I$ & $p$ \\
\hline Technology Use & Parental Control & -0.12 & 0.03 & $-0.18--0.07$ & $<0.001$ \\
\hline Technology Use & Sleep Duration & -0.10 & 0.04 & $-0.16--0.04$ & 0.005 \\
\hline Parental Control & Technology Use & -0.04 & 0.02 & $-0.08-0.004$ & 0.068 \\
\hline Parental Control & Sleep Duration & -0.04 & 0.02 & $-0.08--0.005$ & 0.066 \\
\hline Sleep Duration & Technology Use & -0.06 & 0.03 & $-0.11-0.01$ & 0.049 \\
\hline Sleep Duration & Parental Control & 0.03 & 0.03 & $-0.02-0.08$ & 0.301 \\
\hline Wave 2 & Wave 3 & $\boldsymbol{\beta}$ & SE & $95 \% C I$ & $p$ \\
\hline Technology Use & Parental Control & -0.11 & 0.03 & $-0.15--0.06$ & $<0.001$ \\
\hline Technology Use & Sleep Duration & -0.10 & 0.04 & $-0.16--0.05$ & 0.003 \\
\hline Parental Control & Technology Use & -0.04 & 0.02 & $-0.08-0.004$ & 0.069 \\
\hline Parental Control & Sleep Duration & 0.05 & 0.03 & $-0.09-0.005$ & 0.062 \\
\hline Sleep Duration & Technology Use & -0.05 & 0.03 & $-0.10-0.009$ & 0.050 \\
\hline Sleep Duration & Parental Control & 0.03 & 0.03 & $-0.02-0.07$ & 0.301 \\
\hline
\end{tabular}

Note: Model Fit: $X^{2}(N=473)=41.16, d f=24, \mathrm{CFI}=0.98, \mathrm{TLI}=0.97, \mathrm{RMSEA}=0.039$

Adjusted significance levels $=\mathrm{p} \leq .034$ 


\subsubsection{Daytime Sleepiness}

Table 9 provides standardised beta coefficients for all autoregressive and cross-lagged paths in the model investigating the direct relationship between technology use and daytime sleepiness. More time spent using technology predicted increased daytime sleepiness from Wave 1 and 2 to Wave 2 and 3, respectively. Daytime sleepiness did not predict changes in technology use over time.

Table 9.

Standardised Beta coefficients and 95\% confidence intervals for all autoregressive and cross-lagged paths between school day technology use and daytime sleepiness in Wave 1,

Wave 2 and Wave 3, controlling for sex.

\section{Autoregressive Paths}

\begin{tabular}{cccccc}
\hline Wave 1 & Wave 2 & $\boldsymbol{\beta}$ & SE & $\mathbf{9 5 \%} \boldsymbol{C I}$ & $\boldsymbol{p}$ \\
\hline Technology Use & Technology Use & 0.50 & 0.03 & $0.44-0.55$ & $<.001$ \\
\hline Sleepiness & Sleepiness & 0.50 & 0.03 & $0.45-0.56$ & $<.001$ \\
\hline Wave 2 & Wave 3 & $\boldsymbol{\beta}$ & SE & $\mathbf{9 5 \%} \boldsymbol{C I}$ & $\boldsymbol{p}$ \\
\hline Technology Use & Technology Use & 0.49 & 0.03 & $0.44-0.54$ & $<.001$ \\
\hline Sleepiness & Sleepiness & 0.48 & 0.03 & $0.42-0.53$ & $<.001$ \\
\hline Wave 1 & Wave 3 & $\boldsymbol{\beta}$ & SE & $\mathbf{9 5 \%} \boldsymbol{C I}$ & $\boldsymbol{p}$ \\
\hline Technology Use & Technology Use & 0.24 & 0.04 & $0.18-0.31$ & $<.001$ \\
\hline Sleepiness & Sleepiness & 0.20 & 0.04 & $0.13-0.26$ & $<.001$ \\
\hline Wave 1 & Cross-lagged Paths & & & \\
\hline Technology Use & Wave 2 & $\boldsymbol{\beta}$ & SE & $\mathbf{9 5 \%} \boldsymbol{C I}$ & $\boldsymbol{p}$ \\
\hline Sleepiness & Sleepiness & 0.09 & 0.03 & $0.04-0.14$ & $<0.001$ \\
\hline Wave 2 & Technology Use & 0.06 & 0.03 & $0.01-0.11$ & 0.047 \\
\hline Technology Use & Wave 3 & $\boldsymbol{\beta}$ & SE & $\mathbf{9 5 \%} \boldsymbol{C I}$ & $\boldsymbol{p}$ \\
\hline Sleepiness & Sleepiness & 0.08 & 0.03 & $0.04-0.13$ & 0.002 \\
\hline$N o t e:$ Modi Fit: $X^{2}(N)$ & Technology Use & 0.06 & 0.03 & $0.01-0.11$ & 0.046 \\
\hline
\end{tabular}

Note: Model Fit: $X^{2}(N=496)=24.77, d f=11$, CFI $=0.98$, TLI $=0.97$, RMSEA $=0.050$

Adjusted significance levels $=\mathrm{p} \leq .034$. 
Figure 5 depicts the statistically significant paths in the cross-lagged model investigating the relationship between time spent using technology on school days, parental control of technology use and daytime sleepiness. Table 10 displays the standardised beta coefficients for all autoregressive and cross-lagged paths. Greater daytime sleepiness predicted more time spent using technology on school days and less parental control of technology use from Wave 1 to Wave 2, and from Wave 2 to Wave 3. Longer time spent using technology also predicted less parental control of technology use from Wave 1 to Wave 2 and from Wave 2 to Wave 3. No other significant cross-lagged paths emerged. Given the significant paths between Wave 1 daytime sleepiness, Wave 2 time spent using technology on school days (possible mediator) and Wave 3 parental control of technology use, mediation was assessed, however the indirect effect was non-significant $(\beta=-.007, \mathrm{SE}=.004, p=$ $.061)$.

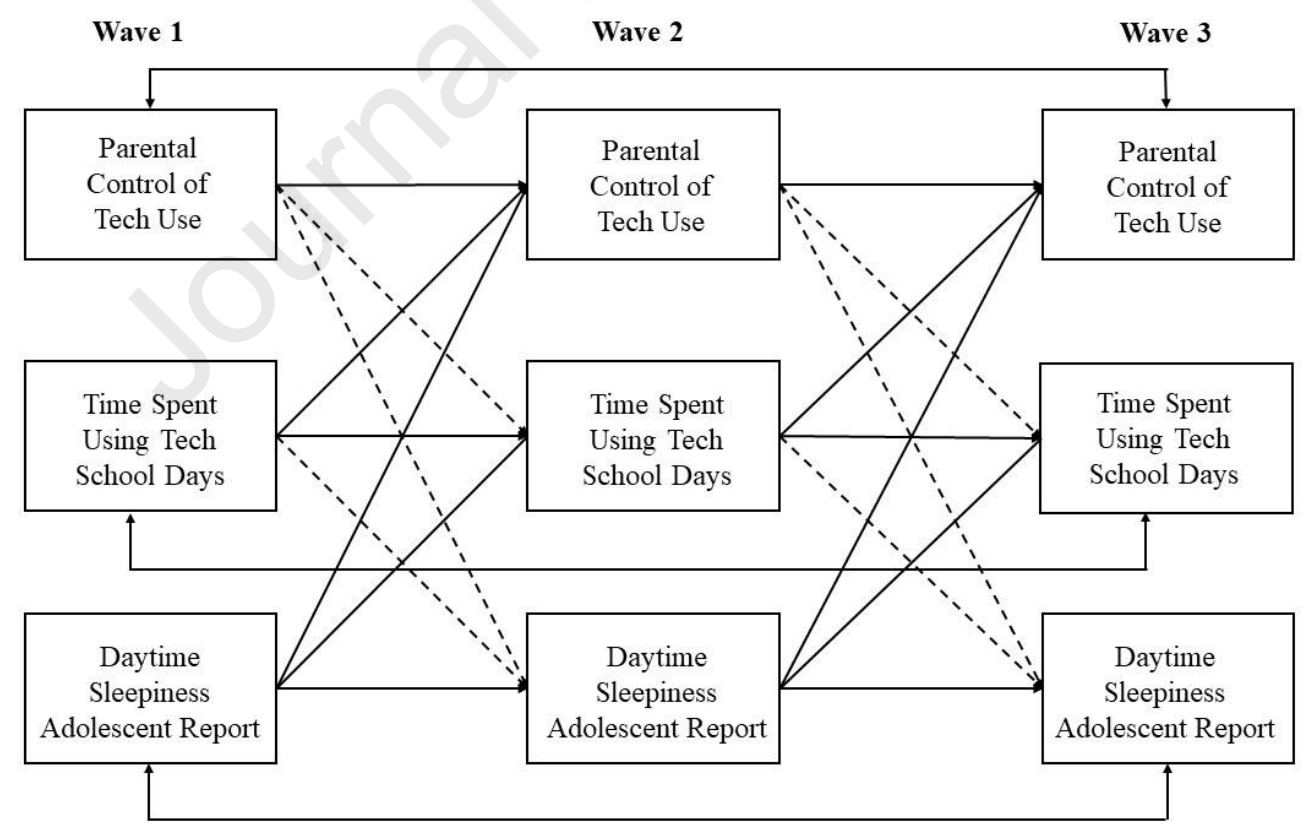

Figure 5. Schematic illustrating the statistically significant relationships between technology use on school days, parental control of technology use and adolescent-reported daytime sleepiness at Wave 1, Wave 2 and Wave 3. Solid lines = significant paths, dashed lines = non-significant paths. 
Table 10.

Standardised Beta coefficients and 95\% confidence intervals for all autoregressive and

cross-lagged paths between school day technology use, parental control of technology use,

and daytime sleepiness in Wave 1, Wave 2 and Wave 3, controlling for sex.

\section{Autoregressive Paths}

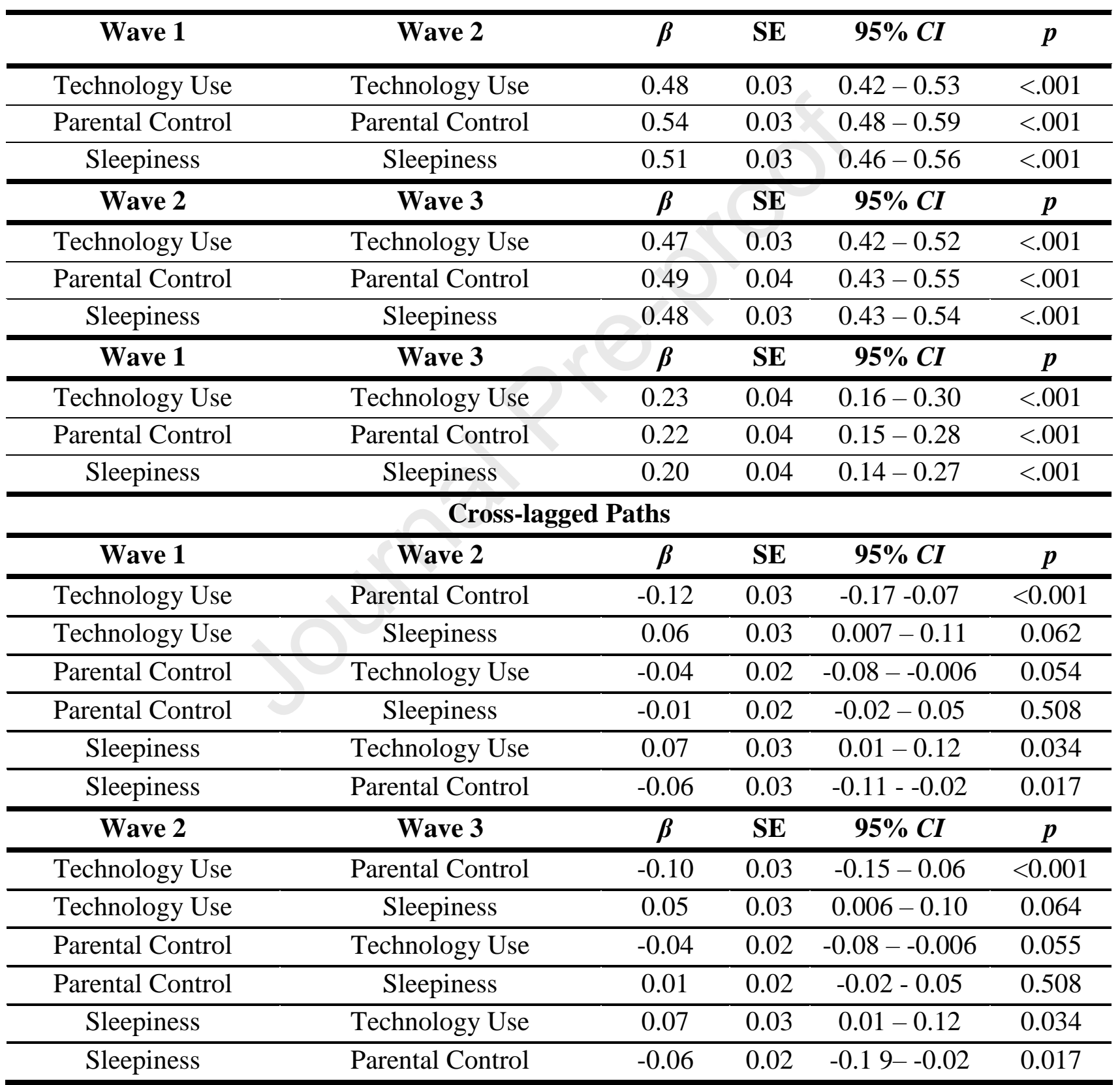

Note: Model Fit: $X^{2}(N=495)=41.57, d f=24$, CFI $=0.99$, TLI $=0.98$, RMSEA $=0.038$

Adjusted significance levels $=\mathrm{p} \leq .034$ 


\subsubsection{Supplementary Analyses}

With regard to sleep duration, parent-reported data largely supported adolescentreported data; sleep duration and time spent using technology bi-directionally predicted one another (Table S1). When parental control was added to the model, both time spent using technology and school night sleep duration predicted parental control of technology use (Table S2, Figure S1). Technology use no longer predicted parent-reported sleep duration. When looking at technology types separately, results were also largely similar to the technology use composite models. Across all sleep variables, parental control did not predict technology use, nor sleep/ sleepiness. In the morning/eveningness models, evening diurnal preference predicted greater internet use and video gaming, yet not social media use or TV watching (Tables S3-6). For adolescent-reported sleep duration, greater internet use, social media use and TV watching predicted shorter sleep duration, yet video gaming did not predict sleep duration (Table S7-10). Tech type and tech composite models differed to the greatest extent for daytime sleepiness. Unlike in the technology composite model, internet use, social media use, TV watching and video gaming did not separately predict increased daytime sleepiness, whereas TV watching predicted greater daytime sleepiness (Tables S15$18)$.

\section{Discussion}

This study investigated longitudinal bi-directional associations between time spent using technology on school days and adolescent sleep (morning/eveningness, school night sleep duration, daytime sleepiness) in a sample of early adolescents, over three waves across a two year period. Given parental limit setting may mitigate the effect of technology use on adolescent sleep (Khor, McClure, Aldridge, Bei, \& Yap, 2020), we also examined whether parental control of technology use protected adolescents from shifting towards an evening 
diurnal preference, inadequate sleep duration and daytime somnolence, via reducing time spent using technology.

\subsection{Technology Use and Adolescent Sleep}

In support of previous research, there were small-to-moderate cross-sectional associations between adolescent sleep and time spent using technology on school days (Bartel et al., 2016; Carter et al., 2016; Hale \& Guan, 2015). In terms of the direct longitudinal associations, those with a greater evening diurnal preference showed a greater increase in technology use on school days over time. However, technology use did not predict changes in diurnal preference over time. The relationship between diurnal preference and technology use has not been examined longitudinally with adolescents, therefore these results are novel. However, our findings are broadly consistent with studies conducted in university students, in that young people with sleep problems have been observed to spend longer watching television and using social media over time (Tavernier \& Willoughby, 2014). Sleep onset difficulties are common in those with an evening diurnal preference, and these results may suggest young people use technology as a sleep aid (Eggermont \& Van den Bulck, 2006), or that technology is used to fill new-found time in the evening until adolescents feel ready to sleep.

Bi-directional associations emerged between time spent using technology on school days and school night sleep duration. Previous longitudinal studies that have investigated associations separately by device/ technology type have shown mixed findings (Nuutinen et al., 2013; Patte et al., 2018; van der Schuur et al., 2019). For example, television may not be as clearly linked to sleep in young people as use of computers (Nuutinen et al., 2013; Poulain et al., 2019). However, the results of the current study support those of Mazzer and colleagues (2018) who similarly used a composite measure of technology use (i.e., TV, 
computer, smartphone) in their two wave, one year, study. Importantly, bi-directional associations in the current study were evident across three waves spanning two years, and findings were replicated across multiple respondents; both of which suggest a robust, yet modest, effect. As proposed by Mazzer and colleagues (2018), adolescents may initially use technology as a sleep aid, yet given technology is engaging, young people may inadvertently be curtailing sleep duration further through sleep displacement (i.e., ceasing use of devices later than intended).

In terms of daytime functioning, more time spent using technology on school days predicted greater daytime sleepiness over time, yet daytime sleepiness did not predict changes in technology use. These findings partially support those of Poulain and colleagues (2019), except Poulain also found daytime sleepiness predicted increased TV use one year later in 10-17 years olds. The difference in findings may be due to age differences between the samples (our sample of young adolescents was homogenous and relatively young), or could be attributable to unique effects by device type, which we did not explicitly examine here. In sum, findings from this study suggest time spent using technology may be a risk factor for short sleep duration and daytime sleepiness in adolescence, yet evening diurnal preference and shorter sleep duration may inversely contribute to increased technology use over time.

\subsection{Parental Control of Technology Use}

While parental control over technology use was found to be cross-sectionally related to both time spent using technology and adolescent sleep, supporting previous research (Buxton et al., 2015; Gau et al., 2007; Pieters et al., 2014), parental control of technology did not predict decreases in time spent using technology on school days, nor improvements in adolescent sleep, over time. Instead, more time spent using technology, greater eveningness 
preference and greater daytime sleepiness predicted decreases in parental control over technology use longitudinally. Previous longitudinal studies have only investigated the relationship from parenting to subsequent sleep, yet these results highlight the importance of considering bi-directional relations (Gentile et al., 2014; Maume, 2013), and support the notion that parenting is a dynamic process, with child and adolescent sleep also influencing parental cognitions and behaviour (Erath \& Tu, 2011). It is possible that parents perceive more control over their child's technology use, when their child spends less time using technology and sleeps well, and that parental control of technology use becomes more difficult when the child uses technology more. Additionally when indicators of problematic sleep are present parents might accommodate to their child's desires to use technology. While it has been suggested that interventions aiming to reduce time spent using technology could harness parental support (Mazzer et al., 2018), the current findings suggest parental limit setting may not result in changes in technology use, nor sleep. However, given the limited research in this area, we recommend further longitudinal and experimental studies (e.g., explicitly manipulating, rather than observing, parental limit setting, such as through training).

\subsection{Theoretical and Developmental Implications}

Results from the present study provide support for the perfect storm model of adolescent sleep, particularly in providing evidence that external alerting factors may interact with the circadian and sleep homeostatic systems to reinforce delayed sleep timing, insufficient sleep duration and daytime sleepiness in adolescents (Crowley et al., 2018). As normative delays in circadian timing occur, and adolescents develop an affinity for the evening, they are likely to spend longer using technology to pass time until they are ready for sleep. Sleep problems (i.e., sleep onset difficulties, short sleep duration) tend to emerge in the second decade of life, therefore technology may also be used as a sleep aid. Given technology 
is designed to be engaging, it is possible that technology use in the evening may disrupt the normal build of up homeostatic sleep pressure (i.e., sleepiness) due to increased cognitive and physiological arousal (Cain \& Gradisar, 2010), or that adolescents enter a state of flow (i.e., fully immersed and lacking a sense of time) causing them to inadvertently go to bed later and obtain less sleep (Smith, King, Richardson, Roane, \& Gradisar, 2017). Further, screen light from technological devices may exacerbate delay circadian timing, via suppression of melatonin, and/or alter sleep architecture (Hale et al., 2018).

It should first be acknowledged that the longitudinal associations showed small effects (i.e., sleep and technology use accounts for a small proportion of the variance in each), suggesting many other factors likely affect adolescent sleep and technology use. With this in mind, results suggest that technology use may exacerbate insufficient school night sleep duration and daytime sleepiness. Indeed, in Wave 2 and Wave 3, on average, participants were obtaining less than the recommended amount of sleep as suggested by the National Sleep Foundation (i.e., 9-11 hours for 6-13 year-olds). Developmentally normal increases in eveningness predicted greater technology use, so it may be beneficial to educate teens on the importance of sleep and the effect of technology use, and encourage them to swap evening technology use with activities unlikely to affect (or even promote) sleep (e.g., reading, spending time with family) (Harbard, Allen, Trinder, \& Bei, 2016), or to instigate a "stop time" for technology use, which has shown to be effective (Bartel, Scheeren, \& Gradisar, 2019).

The current study showed no significant effect of parental control of technology use on actual technology use or adolescent sleep. Existing research suggests that adolescent factors (e.g., heart rate variability, risk taking, flow) can moderate the relationship between technology use and sleep (Hale et al., 2018). Therefore, it may be more effective to work with adolescents directly to mitigate any effect of technology use, or to work with teens and 
parents together to develop mutually agreed controls. In this endeavour, it seems integral to target adolescent motivation to change technology use (Bartel et al., 2019). Whilst outside the scope of the current study, it has been suggested that removing technology from adolescents who actually have a sleep problem may be harmful (Bartel \& Gradisar, 2017). Given adolescents often use technology as a sleep aid (Eggermont \& Van den Bulck, 2006), reducing technology use may exacerbate repetitive negative thinking and thus, sleep problems (Bartel \& Gradisar, 2017). Therefore, a harm minimisation approach may be more appropriate in these circumstances. However, empirical evidence is needed to support this hypothesis.

\subsection{Limitations and Future Directions}

While the current study had a number of strengths, including comprehensive, multiinformant measurement of sleep, and good participant retention, results should be interpreted with the study's limitations in mind. Firstly, total time spent using technology was estimated via self-report for television, video game, internet and social media use, therefore there are likely forms of technology that were not captured in this study (e.g., computer/tablet/mobile phone use), and estimates are subject to reporter biases. Many of the possible mechanisms linking technology use with sleep relate to technology use in the evening, whereas the time of technology use was not isolated to the evening in the current study. Further research is needed to uncover mechanisms linking technology use with sleep in adolescence, and results from the current study suggest the need to focus on adolescent, rather than parental, factors.

Whilst the multi-informant measurement of school night sleep duration was a strength of the study, sleep diaries and actigraphy would have yielded more reliable estimates. While morning/evening preference is related to underlying circadian timing, sleep and circadian timing are not synonymous, therefore future longitudinal studies may also wish to measure 
circadian markers. The sample in the current study was homogenous in terms of age, and relationships between sleep and technology were only investigated in the early adolescent period. Sample characteristics may explain some differences in results with previous studies, and it is possible that a different pattern of results may be observed later in the adolescent developmental period. Finally, cross-lagged associations were observational and small in nature and replication of the findings is essential. More longitudinal studies are needed, as well as well-designed experimental studies.

\subsection{Conclusions}

Results from the current study add to evidence supporting a bi-directional relationship between technology use and sleep in adolescence, and lend support for the perfect storm model of adolescent sleep (Carskadon, 2011; Crowley et al., 2018). Psychosocial pressures likely interact with bio-regulatory sleep processes, contributing to the ubiquitous trend towards delayed sleep timing, inadequate sleep, and daytime sleepiness across adolescence. While parental restriction of technology use has been suggested as a promising adjunct to adolescent sleep interventions (Mazzer et al., 2018), results from the current study suggest parental control of technology may not predict prospective changes in adolescent technology use, nor sleep, over time. While replication of this effect is needed, future research could focus on findings creative ways in which adolescents themselves can mitigate their risk of inadequate sleep.

\section{Acknowledgements}

The authors extend their gratitude to Justin Freeman and the research assistants on the RAW project for data collection, and to our participants.

Funding: The RAW Project was supported by the Australian Research Council under Grant Number FL150100096. 


\section{References}

Bartel, K., \& Gradisar, M. (2017). New Directions in the Link Between Technology Use and Sleep in Young People. In Sleep Disorders in Children (pp. 69-80): Springer.

Bartel, K., Scheeren, R., \& Gradisar, M. (2019). Altering adolescents' pre-bedtime phone use to achieve better sleep health. Health communication, 34(4), 456-462.

Bartel, K., Williamson, P., van Maanen, A., Cassoff, J., Meijer, A., Oort, F., . . Gradisar, M. (2016). Protective and risk factors associated with adolescent sleep: findings from Australia, Canada, and The Netherlands. Sleep Medicine, 26, 97-103.

Benjamini, Y., \& Hochberg, Y. (1995). Controlling the false discovery rate: a practical and powerful approach to multiple testing. Journal of the Royal statistical society: series B (Methodological), 57(1), 289-300.

Borlase, B., Gander, P., \& Gibson, R. (2013). Effects of school start times and technology use on teenagers' sleep: 1999-2008. Sleep and Biological Rhythms, 11(1), 46-54.

Buxton, O., Chang, A., Spilsbury, J., Bos, T., Emsellem, H., \& Knutson, K. (2015). Sleep in the modern family: protective family routines for child and adolescent sleep. Sleep Health, 1(1), 15-27.

Cain, N., \& Gradisar, M. (2010). Electronic media use and sleep in school-aged children and adolescents: A review. Sleep Medicine, 11(8), 735-742.

Carskadon, M. (2011). Sleep in adolescents: the perfect storm. Pediatric Clinics of North America, 58(3), 637.

Carskadon, M., Seifer, R., \& Acebo, C. (1991). Reliability of six scales in a sleep questionnaire for adolescents. Sleep Research, 20, 421.

Carter, B., Rees, P., Hale, L., Bhattacharjee, D., \& Paradkar, M. (2016). Association between portable screen-based media device access or use and sleep outcomes: a systematic review and meta-analysis. JAMA pediatrics, 170(12), 1202-1208.

Crowley, S., Wolfson, A., Tarokh, L., \& Carskadon, M. (2018). An update on adolescent sleep: New evidence informing the perfect storm model. Journal of Adolescence, 67, 55-65.

Drake, C., Nickel, C., Burduvali, E., Roth, T., Jefferson, C., \& Badia, P. (2003). The Pediatric Daytime Sleepiness Scale (PDSS): sleep habits and school outcomes in middle-school children. Sleep: Journal of Sleep and Sleep Disorders Research, 26(4), 455-458.

Eggermont, S., \& Van den Bulck, J. (2006). Nodding off or switching off? The use of popular media as a sleep aid in secondary-school children. Journal of Paediatrics and Child Health, 42, 428-433.

Erath, S., \& Tu, K. (2011). The parenting context of children's sleep. In Sleep and development: Familial and socio-cultural considerations (pp. 29-47).

Fossum, I., Nordnes, L., Storemark, S., Bjorvatn, B., \& Pallesen, S. (2014). The association between use of electronic media in bed before going to sleep and insomnia symptoms, daytime sleepiness, morningness, and chronotype. Behavioral Sleep Medicine, 12(5), 343-357.

Gau, S., Shang, C., Merikangas, K., Chiu, Y., Soong, W., \& Cheng, A. (2007). Association between morningness-eveningness and behavioral/emotional problems among adolescents. Journal of Biological Rhythms, 22(3), 268-274.

Gentile, D., Reimer, R., Nathanson, A., Walsh, D., \& Eisenmann, J. (2014). Protective effects of parental monitoring of children's media use: A prospective study. JAMA pediatrics, 168(5), 479-484.

Giannotti, F., Cortesi, F., Sebastiani, T., \& Ottaviano, S. (2002). Circadian preference, sleep and daytime behaviour in adolescence. Journal of Sleep Research, 11(3), 191-199. 
Gradisar, M., Gardner, G., \& Dohnt, H. (2011). Recent worldwide sleep patterns and problems during adolescence: A review and meta-analysis of age, region, and sleep. Sleep Medicine, 12, 110-118.

Hale, L., \& Guan, S. (2015). Screen time and sleep among school-aged children and adolescents: a systematic literature review. Sleep Medicine Reviews, 21, 50-58.

Hale, L., Kirschen, G., LeBourgeois, M., Gradisar, M., Garrison, M., Montgomery-Downs, H., ... Buxton, O. (2018). Youth screen media habits and sleep: sleep-friendly screen behavior recommendations for clinicians, educators, and parents. Child and Adolescent Psychiatric Clinics, 27(2), 229-245.

Harbard, E., Allen, N., Trinder, J., \& Bei, B. (2016). What's keeping teenagers up? Prebedtime behaviors and actigraphy-assessed sleep over school and vacation. Journal of Adolescent Health, 58(4), 426-432.

Johansson, A., Petrisko, M., \& Chasens, E. (2016). Adolescent sleep and the impact of technology use before sleep on daytime function. Journal of pediatric nursing, 31(5), 498-504.

Kauderer, S., \& Randler, C. (2013). Differences in time use among chronotypes in adolescents. Biological Rhythm Research, 44(4), 601-608.

Keyes, K., Maslowsky, J., Hamilton, A., \& Schulenberg, J. (2015). The great sleep recession: Changes in sleep duration among US adolescents, 1991-2012. Pediatrics, 135(3), 460-468.

Khor, S., McClure, A., Aldridge, G., Bei, B., \& Yap, M. (2020). Modifiable parental factors in adolescent sleep: A systematic review and meta-analysis. Sleep Medicine Reviews, 101408.

Matricciani, L., Olds, T., \& Petkov, J. (2012). In search of lost sleep: secular trends in the sleep time of school-aged children and adolescents. Sleep Medicine Reviews, 16(3), 203-211.

Maume, D. (2013). Social ties and adolescent sleep disruption. Journal of Health and Social Behavior, 54(4), 498-515.

Mazzer, K., Bauducco, S., Linton, S., \& Boersma, K. (2018). Longitudinal associations between time spent using technology and sleep duration among adolescents. Journal of Adolescence, 66, 112-119.

Muthén, L., \& Muthén, B. (2015). Mplus. The comprehensive modelling program for applied researchers: user's guide, 5 .

Nuutinen, T., Ray, C., \& Roos, E. (2013). Do computer use, TV viewing, and the presence of the media in the bedroom predict school-aged children's sleep habits in a longitudinal study? BMC public health, 13(1), 684.

Patte, K., Qian, W., \& Leatherdale, S. (2018). Modifiable predictors of insufficient sleep durations: a longitudinal analysis of youth in the COMPASS study. Preventive medicine, 106, 164-170.

Pieters, D., De Valck, E., Vandekerckhove, M., Pirrera, S., Wuyts, J., Exadaktylos, V., ... Cluydts, R. (2014). Effects of pre-sleep media use on sleep/wake patterns and daytime functioning among adolescents: the moderating role of parental control. Behavioral Sleep Medicine, 12(6), 427-443.

Polos, P., Bhat, S., Gupta, D., O'Malley, R., DeBari, V., Upadhyay, H., . . Chokroverty, S. (2015). The impact of Sleep Time-Related Information and Communication Technology (STRICT) on sleep patterns and daytime functioning in American adolescents. Journal of Adolescence, 44, 232-244.

Poulain, T., Vogel, M., Buzek, T., Genuneit, J., Hiemisch, A., \& Kiess, W. (2019). Reciprocal longitudinal associations between adolescents' media consumption and sleep. Behavioral Sleep Medicine, 17(6), 763-777. 
Satorra, A. (2000). Scaled and adjusted restricted tests in multi-sample analysis of moment structures. In Innovations in multivariate statistical analysis (pp. 233-247): Springer.

Shimura, A., Hideo, S., Takaesu, Y., Nomura, R., Komada, Y., \& Inoue, T. (2018). Comprehensive assessment of the impact of life habits on sleep disturbance, chronotype, and daytime sleepiness among high-school students. Sleep Medicine, 44, 12-18.

Smith, L., King, D., Richardson, C., Roane, B., \& Gradisar, M. (2017). Mechanisms influencing older adolescents' bedtimes during videogaming: the roles of game difficulty and flow. Sleep Medicine, 39, 70-76.

Tarokh, L., Short, M., Crowley, S., Fontanellaz-Castiglione, C., \& Carskadon, M. (2019). Sleep and Circadian Rhythms in Adolescence. Current sleep medicine reports, 1-12.

Tavernier, R., \& Willoughby, T. (2014). Sleep problems: predictor or outcome of media use among emerging adults at university? Journal of Sleep Research, 23(4), 389-396.

van der Schuur, W., Baumgartner, S., \& Sumter, S. (2019). Social media use, social media stress, and sleep: Examining cross-sectional and longitudinal relationships in adolescents. Health communication, 34(5), 552-559. 


\section{Highlights}

- There is a robust association between technology use and adolescent sleep

- It is unclear if parental control of technology mitigates risk to adolescent sleep

- Results suggest a bi-directional relationship between technology use and sleep

- Parental control did not predict adolescent technology use, nor sleep

- Broadly, findings lend support for the perfect storm model of adolescent sleep 
C.E.R. participated in the design, analysis and coordination of the study and drafted the manuscript; N.R.M. participated in the design, analysis and coordination of the study and helped draft the manuscript; J.F. participated in the design and coordination of the study and helped draft the manuscript; E.L.O. participated in the design and coordination of the study and helped draft the manuscript; C.J.J. participated in the design and coordination of the study and helped draft the manuscript; R.M.R. conceived this study, and participated in its design and helped draft the manuscript. All authors read and approved the final manuscript. 